\title{
Commentary \\ Ingredients for adequate evaluation of blood glucose algorithms as applied to the critically ill
}

\author{
Tom Van Herpe ${ }^{1}$, Bart De Moor ${ }^{1}$ and Greet Van den Berghe ${ }^{2}$
}

\begin{abstract}
1'Department of Electrical Engineering (ESAT - SCD), Katholieke Universiteit Leuven, Kasteelpark Arenberg 10, B-3001 Heverlee, Leuven, Belgium ${ }^{2}$ Department of Intensive Care Medicine, University Hospital Gasthuisberg, Katholieke Universiteit Leuven, Herestraat, B-3000 Leuven, Belgium
\end{abstract}

Corresponding author: Tom Van Herpe, tom.vanherpe@esat.kuleuven.be

Published: 7 January 2009

Critical Care 2009, 13:102 (doi:10.1186/cc7115)

This article is online at http://ccforum.com/content/13/1/102

(C) 2009 BioMed Central Ltd

See related research by Eslami et al., http://ccforum.com/content/12/6/R139

\begin{abstract}
The article by Eslami and colleagues provides an overview of the indicators used to measure the quality of blood glucose control in patients admitted to the intensive care unit. Each indicator can be related to one or more of the following categories: blood glucose zones, blood glucose levels, time intervals, and features of the insulin titration algorithm. Some important issues (for instance those concerning the clarity of definitions used for glycaemic thresholds) are raised. This systematic review calls for a practical guide to advise the clinician how different blood glucose signals should (ideally) be evaluated and which steps should to be undertaken.
\end{abstract}

In the previous issue of Critical Care, Eslami and coworkers [1] review the various outcome measures used to evaluate the quality of blood glucose (BG) control (level of 'tight glycaemic control' [TGC]) in critically ill patients; the review considers studies published prior to 2008. We should like to congratulate the authors for their careful search and analysis. They subdivided 30 different indicators into four nonorthogonal categories: BG zones (adverse zones versus in-range zones), BG levels (for example, mean BG), time intervals (for example, time within a predefined BG range), and protocol features (for example, BG sampling frequency).

In recent years, the definition of TGC had appeared to be well established, based on the findings of two randomized controlled clinical trials that clearly demonstrated the relation between strictly regulated BG (80 to $110 \mathrm{mg} / \mathrm{dl}$ ) and reduction in mortality/morbidity $[2,3]$. More recently, however, the level of TGC has emerged as a controversial issue, following publication of the findings of two other (under-powered) clinical trials that were unsuccessful in implementing TGC into daily practice $[4,5]$. Control of BG to achieve a clinically and ethically approved target remains a crucial element in the treatment of intensive care unit (ICU) patients and necessitates the design and assessment of measures that reflect this level of control. The paper by Eslami and coworkers presents an overview of existing indicators, but rigorous assessment to identify the optimal indicator(s) is now required.

Two important facts (already partly discussed by Eslami and coworkers [1]) must be emphasized. First, there is no consensual definition of some methodologies that are currently used as an indicator. Take the definition for 'hypoglycaemia' as an example. Eslami and coworkers identified 15 different thresholds for BG, varying from $<40 \mathrm{mg} / \mathrm{dl}$ to $<72 \mathrm{mg} / \mathrm{dl}$. In some studies any measurement below the threshold is regarded 'hypoglycaemia', whereas other studies take the time dimension into account in order to ensure that multiple hypoglycaemic events occurring over a short interval (for example, 30 minutes) are evaluated as a single event. In still other studies, definitions are not explained, which hampers comparison between different levels of glucose control.

Second, the availability of a near-continuous glucose sensor is a prerequisite for reliable TGC assessment, but no nearcontinuous glucose sensor has yet been found to be sufficiently reliable and accurate for use in critically ill patients. Accordingly, only time-discrete measurements of glycaemia (for instance, a time interval of 1 hour or more) are available, which can be dealt with in two ways. On the one hand, the time dimension can be neglected such that only the effectively measured values are considered in the analysis (for example, mean BG, Glycaemic Penalty Index (GPI) [6], and so on). As Eslami and coworkers correctly point out, this type of analysis may be sensitive to sampling. On the other hand, nonmeasured values can be estimated, leading to a (nonmeasured) continuous glucose signal, allowing application of

$\mathrm{BG}=$ blood glucose; $\mathrm{GPI}=$ Glycaemic Penalty Index; HGI = Hyperglycaemic Index; ICU = intensive care unit; TGC = tight glycaemic control. 
area under the curve indicators (for example, Hyperglycaemic Index [HGl] [7]). Here, however, a typically linear relation between observations is assumed (in order to achieve an approximation to the true, nonlinear dynamics of BG fluctuation), which explains why this second technique can lead to incorrect assessment of BG signals.

Ideally, adequate assessment of a BG signal and comparison with other BG signals require the fulfilment of three conditions. The first of these is consensus concerning the desired target BG range (and definitions of hypoglycaemia/hyperglycemia). The two landmark studies $[2,3]$ and a new clinical trial [8] have shown that achieving age-adjusted strict normoglycaemia throughout the ICU stay leads to lower ICU mortality and morbidity, in both adult and paediatric ICU patients. Second, the use of future reliable near-continuous glucose sensors will permit appropriate consideration of the time dimension in the indicator. Accordingly, duration and magnitude of hypoglycaemic/hyperglycemic events are represented more precisely, as compared with time-discrete BG signals. Third, clinicians must be aware that traditional measures (for instance, mean BG) potentially can confound evaluation, as previously discussed [6].

More advanced indicators such as $\mathrm{HGl}$ and GPI (note that GPI, introduced in 2008 [6], was not evaluated by Eslami and coworkers [1]) are indispensable for adequate assessment of the overall level of BG control and are less complex than is sometimes claimed. Indeed, the HGl (and, analogously, the Hypoglycaemic Index [9]) and GPI combine the first three categories mentioned by Eslami and coworkers [1]: BG zones, BG levels and time intervals. While we await the availability of near-continuous glucose monitoring devices, we advise clinicians to compute both $\mathrm{HGI}$ and GPI (per patient), because these indicators compensate for each other's weaknesses. Next, population $\mathrm{HGl}$ and $\mathrm{GPI}$ values can be obtained by computing the median and $25 \%$ to $75 \%$ interquartile range, because most BG distributions are nonnormal. Finally, it is important to note (particularly when comparing different $B G$ signals) the impact that study design (BG sampling frequency and duration of algorithm application) has on the level of BG control [6].

\section{Competing interests}

The authors declare that they have no competing interests.

\section{Acknowledgements}

The research was supported by various organizations and grants. BDM and $\mathrm{GVdB}$ are both supported by the Flemish Government (FWO: G.0557.08). BDM is supported by the following: Research Council KUL (GOA AMBioRICS, CoE EF/05/006, IOFSCORES4CHEM, several $\mathrm{PhD} /$ postdoc and fellow grants), the Flemish Government (FWO: PhD/postdoc grants, projects G.0452.04, G.0499.04, G.0211.05, G.0226.06, G.0321.06, G.0302.07, G.0320.08, G.0558.08, research communities; IWT: PhD Grants, McKnow-E, Eureka-Flite+), the Belgian Federal Science Policy Office (IUAP P6/04), EU (ERNSI; FP7-HD-MPC), Contract Research (AMINAL) and Helmholtz (viCERP). GVdB is supported by the following: Research Council KUL (GOA/2007/14, OT/03/56), the Flemish Government
(FWO: G.0533.06) and the Methusalem Program, funded by the Flemish Government.

\section{References}

1. Eslami S, de Keizer NF, de Jonge E, Schultz MJ, Abu-Hanna A: A systematic review on quality indicators for tight glycaemic control in critically ill patients: need for an unambiguous indicator reference subset. Crit Care 2008, 12:R139.

2. Van den Berghe G, Wouters P, Weekers F, Verwaest C, Bruyninckx F, Schetz M, Vlasselaers D, Ferdinande P, Lauwers P, Bouillon R: Intensive insulin therapy in the critically ill patients. $N$ Engl J Med 2001, 345:1359-1367.

3. Van den Berghe $G$, Wilmer A, Hermans G, Meersseman W, Wouters P, Milants I, Van Wijngaerden E, Bobbaers H, Bouillon $\mathrm{R}$ : Intensive insulin therapy in the medical ICU. $N$ Engl J Med 2006, 354:449-461.

4. Brunkhorst FM, Engel C, Bloos F, Meier-Hellmann A, Ragaller M, Weiler N, Moerer O, Gruendling M, Oppert M, Grond S, Olthoff D, Jaschinski U, John S, Rossaint R, Welte T, Schaefer M, Kern P, Kuhnt E, Kiehntopf M, Hartog C, Natanson C, Loeffler M, Reinhart $\mathrm{K}$ : Intensive insulin therapy and pentastarch resuscitation in severe sepsis. N Engl J Med 2008, 358:125-139.

5. Preiser JC, Devos P: Clinical experience with tight glucose control by intensive insulin therapy. Crit Care Med 2007, 35:S503-S507.

6. Van Herpe T, De Brabanter J, Beullens M, De Moor B, Van den Berghe G: Glycemic Penalty Index for adequately assessing and comparing different blood glucose control algorithms. Crit Care 2008, 12:R24.

7. Vogelzang M, van der Horst I, Nijsten M: Hyperglycaemic index as a tool to assess glucose control: a retrospective study. Crit Care 2004, 8:122-127.

8. Vlasselaers D, Milants I, Desmet L, Wouters PJ, Vanhorebeek I, van den Heuven I, Mesotten D, Casaer M, Meyfroidt G, Ingels C, Muller J, Van Cromphaut S, Schetz M, Van den Berghe G: The effect of targeting age-adjusted normoglycemia with insulin infusion in pediatric ICU patients: a large RCT. Endocrinol Metab 2008, 52(Suppl. 6):S694.

9. Mackenzie I, Ingle S, Zaidi S, Buczaski S: Hypoglycaemia? So what! Intensive Care Med 2006, 32:620-621. 